Social Work/Maatskaplike Werk Vol 50 No 2; (7)

http://socialwork.journals.ac.za/pub. http://dx.doi.org/10.15270/50-2-399

\title{
FACTORS CONTRIBUTING TO ELDER ABUSE AND NEGLECT IN THE INFORMAL CAREGIVING SETTING
}

Janetta Ananias, University of Namibia, Windhoek, Herman Strydom, North-West University, Potchefstroom Campus, South Africa

Abstract

This article provides an overview of factors contributing to elder abuse and neglect within the informal caregiving setting from the perspective of ecological theory. This theory offers a deeper understanding of the complexity of elder abuse by considering the interactions that take place across a number of interrelated systems as well as the multiple risk factors that contribute to elder abuse and neglect. Researchers, policy makers and practitioners need to develop awareness of the risk factors regarding elder abuse and neglect, and to develop appropriate interventions in response to elder abuse and neglect. 



\section{FACTORS CONTRIBUTING TO ELDER ABUSE AND NEGLECT IN THE INFORMAL CAREGIVING SETTING}

\section{Janetta Ananias, Herman Strydom}

\section{INTRODUCTION}

Elder abuse is a relatively new phenomenon which was initially referred to as "granny battering" in the 1970s (Ayres \& Woodtli, 2001:328; Brook, 2008:46; Richardson, Kitchen \& Livingston, 2002:335; Selwood, Cooper \& Livingston, 2007:1009). Groundbreaking work on elder abuse was initiated in the UK and the USA, but with different perceptions of the settings of elder abuse. In the UK the focus of elder abuse was within medical and institutional settings, while in the USA elder abuse was observed as a family and domestic violence problem (Habjanic \& Lahe, 2012:261). As a result of the shift from institutional care to community care, most older people live in the family and domestic environment (Van Rensburg \& Strydom, 2010:381); therefore this paper will focus on elder abuse in the family and domestic milieu.

According to Lowenstein (2010:283), initial surveys on elder abuse conducted in the 1970s as first-generation studies could not be generalised because of vital sampling and methodological limitations. Subsequent studies conducted in the 1980s, referred to as second-generation studies, made improvements in their methodology, which also led to the advancement of national studies on elder abuse. Eventually, elder abuse was recognised as a global concern (Kalache \& Blewitt, 2012:89), but the problem of elder abuse remains an under-researched topic.

\section{PROBLEM STATEMENT}

Many older people live in extended, multigenerational households and receive informal care from their adult children, partners as well as other family members (Sibai \& Yamout, 2012:65). In fact, Lowenstein (2010:218) considers informal caregiving as a family and an intergenerational issue, which can be fulfilled by many people as a life course role at some point in life.

Even though family members are the main providers of informal care to older persons, Decalmer and Glendenning (cited by Strydom, 2003:77) claim that almost 10\% of older people who are cared for by family caregivers are at risk of elder abuse. There are many explanations for the weakening of the family as an important safety net for older people. Ferreira (2004:6) explains that some children have lost their sense of obligation to care for older relatives. Family structures are also undergoing major changes since adult children no longer live in the same towns as their elderly parents, because of the current socio-economic climate, high costs of living and pressure to find employment. Consequently, a lesser number of family caregivers are available to care for older people (Lowenstein, 2010:219; Peri, Fanslow, Hand \& Parson, 2009:168). Older people are also at risk of abuse by family caregivers who experience difficulties in finding a balance between caregiving and other life activities. Similarly, conflicting intergenerational relations and stress in caregiving may also lead to potential elder abuse and neglect 
(Lowenstein, 2010:223). Furthermore, Lowenstein, Eisikovits, Band-Winterstein \& Enosh (2009:255) comment that switching into the caregiving role can be stressful, as some conditions of aging populations can be chronic and progressive, which may lead to elder abuse and neglect in families.

Within the Namibian context, family relations have also broken down because of urbanisation and migration (Dima, 2003:10). Furthermore, the draft green paper from the Ministry of Health and Social Services (1997:P7-1) maintains that Namibian families are no longer able to care for their older relatives due to poverty and modernisation, as traditional norms to care for older people are fading. The research question for this paper is: "What are the factors contributing to elder abuse and neglect within the informal caregiving setting?"

\section{DEFINITION OF CONCEPTS}

\section{Informal caregiver}

A caregiver can be a family member or any other person who is looking after another person who is unable to look after himself or herself in some or all respects. Informal caregiving takes place in the domestic setting and does not receive any payment (Pierson $\&$ Thomas, 2010:65). The typical caregiver is a spouse or an adult child. Both men and women could be informal caregivers. However, women often perform longer hours of caregiving and provide higher levels of care, and have ended up as caregivers because of fewer options in life (Lowenstein, 2010:218).

\section{Elder abuse}

There are no commonly accepted definitions of elder abuse (Ayres \& Woodtli, 2001:328; Ferreira, 2004:27; Walsh \& Yon, 2012:105). The notion of elder abuse is defined differently by various professionals to fit discipline-specific purposes such as legal, law enforcement, medical or protection requirements (Ayres \& Woodtli, 2001:328). The concept of elder abuse is also understood differently by older people and caregivers (Ayalon, 2011:499-520; Hempton et al., 2011:466-472; Selwood et al., 2007:1009). A widely accepted definition of elder abuse by the International Network for Prevention of Elder Abuse (INPEA) and the World Health Organisation (WHO) (cited by De Donder et al., 2011:303) will be applied in this article. Elder abuse is defined as "a single or repeated act, or lack of appropriate action, occurring within any relationship where there is an expectation of trust, which causes harm or distress to an older person". The definition implies that an abusive act towards an older person could be either an act of commission or omission by any person in a position of trust such as a family member, friend or neighbour.

\section{Types of elder abuse}

There are many types or categories of elder abuse. Ayres and Woodtli (2001:328) mention the difficulty of fitting abusive acts into a specific category of elder abuse, since some abusive acts may not fit one single category or may be appropriate for several categories. In addition, elder abuse situations are complex and these categories do not always reflect those complexities. International scholars have agreed upon five types of 
elder abuse, namely physical abuse, psychological abuse, financial abuse, sexual abuse and neglect (Habjanic \& Lahe, 2012:262). A brief description of each type of elder abuse will be discussed below.

\section{Physical abuse}

The National Centre on Elder Abuse (cited by Mouton et al., 2005:23) defines physical abuse as "the infliction of physical pain, injury, or physical coercion, and involving at least one act of violence including beating, slapping, hitting, burning, cutting, or physical restraint use, or intentional over-medication".

\section{Psychological abuse}

The National Centre on Elder Abuse (cited by Conrad et al., 2011:149) defines emotional or psychological abuse as "the infliction of anguish, pain, or distress through verbal or nonverbal acts. Emotional or psychological abuse includes, but is not limited to, verbal assaults, insults, threats, intimidation, humiliation, and harassment." Some examples of emotional or psychological abuse may also consist of actions such as treating an older person like a child; isolating the older person from his or her family, friends, or regular activities; giving an older person the "silent treatment"; and enforced social isolation.

\section{Financial abuse}

According to Sev'er (2009:280), financial abuse involves exploitative actions such as theft, fraud, forgery as well as charging older people inflated fees for cheaper goods. Severe forms of economic exploitation include selling the property of older people without informed consent, stealing the pension money of older people, or forcing older people to change their will. Other forms of elder abuse also includes forcing older people to take care of grandchildren, refusing to vacate the home of the older person or staying with the older person without making any financial contribution towards the household.

\section{Sexual abuse}

The World Health Organisation (WHO) (cited by De Donder et al., 2011:303) refers to sexual abuse as "non-consensual sexual contact of any kind". Examples of sexual abuse are unwanted intimacy, touching in a sexual way, rape, undressing in front of the victim.

\section{Neglect}

Neglect of older people is the most common type of elder abuse, but it is not easy to prove neglect. Examples of neglect are failure to provide proper nutrition, clothing and hygiene care to bedridden older people, and leaving an injured older person unsupervised (Sev'er, 2009:280-281).

\section{THEORETICAL FRAMEWORK}

The complexity of the problem of elder abuse remains a challenge, because there is no theoretical framework that properly explains the causes of elder abuse (Anetzberger, 2005:10). Only a few theoretical approaches are supported from empirical research. However, more than one theoretical perspective is needed to fully understand the 
problem of elder abuse (Penhale, 2010:239-241). Some well-known theories on elder abuse are, amongst others, learning theory, dependence theory, psychopathology theory, caregiver stress theory, family systems theory, social exchange theory and ecological theory. Because ecological theory considers the interactions that take place across a number of interrelated systems and how they adapt to one another (Miley, O'Melia \& Du Bois, 2004:30), it offers a better explanation of the complexity of the problem of elder abuse and neglect.

According to Shields (2010:22-23), ecological theory is one of the most researched theories for explaining elder abuse. Pierson and Thomas (2010:190) and Teater (2010:24) claim that ecological theory focuses on the adaptive and mutual relationships, interactions and transactions between people and their environment. The ecosystems framework guides practitioners and researchers in establishing proper relationships with clients to assess the functioning of clients and to implement intervention strategies (Miley et al., 2004:49). In the context of elder abuse, the ecological theorist has a keen interest in the relationships and interactions between the older person and the caregiver, as well as within the caregiving and broader societal context (Penhale, 2010:239; Podnieks, Penhale, Goergen, Biggs \& Han, 2010:161; Schiamberg, Barboza, Oehmke, Zhang, Griffore, Robin, Weatherill, Vaon Heydrich \& Post, 2011:195). Ecological theory suggests that elder abuse and neglect may occur within four systems, namely the micro, meso, exo and macro systems (Schiamberg \& Gans, 1999:93-94).

The micro system refers to the relationship between the older person and his or her caregiver. The meso system refers to the relationship between the older person and church or community services, the exo system focuses on the impact of a caregiver's workplace on caregiving, while the macro system refers to the interactions of the older person with health and government services. In later works by Schiamberg et al. (2011:207) the chrono system is added as a fifth level that focuses on the timeframe within which an older person has been in a potentially abusive environment. These systems may overlap, since risk factors found in one system may also appear in another (Schiamberg \& Gans, 1999:93-94). A detailed discussion of all the systems is beyond the scope of this paper, therefore attention will be paid to risk factors for elder abuse in the micro and macro systems.

\section{RISK FACTORS FOR ELDER ABUSE AND NEGLECT}

Knowledge of risk factors to elder abuse is under-researched (Peri et al., 2009:14; Post et al., 2010:325). Furthermore, there is no consensus amongst the few scholars who have worked on risk factors for elder abuse (Kalache \& Blewitt, 2012:89). Ecological theory is useful for understanding the risk factors of elder abuse and neglect. This is because ecological theory offers a broader understanding of risk factors for elder abuse as it applies to the older victim, the perpetrator, the context of caregiving and the broader societal context (Jayawardena \& Liao, 2006:129; Pe'rez-Rojo et al., 2009:17). Moreover, Schiamberg et al. (2011:207), suggest that not only one but several risk factors need to be considered when ecological theory is applied. 


\section{- Individual characteristics: the older victim of abuse and neglect}

There are a number of risk factors related to the older victim of elder abuse. Each of these characteristics will be discussed.

\section{Gender}

There is still a great deal of controversy regarding the gender that is most at risk of elder abuse and neglect (Kravitz, 2006:36; Pe'rez-Rojo, 2009:17; Schiamberg \& Gans, 1999:90; Von Heydrich, 2009:48). There is substantial evidence that older women are more vulnerable to elder abuse and neglect (Ferreira, 2004:19; Lowenstein et al., 2009:271; Peri et al., 2009:164; Rahman \& Gaafary, 2012:534; Von Heydrich, 2009:47; Weeks et al., 2005:10). However, in a community-based prevalence study the World Health Organisation (2002:130) found that older men were equally at risk of being abused by spouses, adult children or other family members. In fact, in a needs assessment in Namibia, Ananias and Strydom (2012) found that older men rather than older women often tend to be victims of neglect.

\section{Chronological age}

The more a person advances in age, the more the physical, psychological and cognitive functioning of the older person deteriorates. These factors may increase the elderly person's chances of being abused and neglected (Horsford et al., 2010:80; Kravitz, 2006:35; Schiamberg \& Gans, 1999:90; Von Heydrich, 2009:48).

\section{Marital status}

There are contradictory findings on marital status as a risk factor. Married women are more at risk of elder abuse than widowed or divorced older women. However, it is not the marital status but rather the living arrangements that place older people at risk of elder abuse and neglect. Therefore, it is more accurate to state that older people who live with someone are at greater risk of abuse than older people who live alone (Kravitz, 2006:36-37; Schiamberg \& Gans, 1999:90; Von Heydrich, 2009:48-49). It is, however, not commonly accepted that this is a general "rule", as shown by Weeks et al. (2005:11), who argue that older people are abused, irrespective of whether they live with a spouse, a family member or alone.

\section{Chronic serious physical health problems}

Older people with serious, chronic physical health problems are more dependent on their caregiver. This dependence can lead to caregiver stress, which causes vulnerability to elder abuse (Ayalon, 2011:503; Kravitz, 2006:37; Nadien, 2006:166; Schiamberg \& Gans, 1999:90; Von Heydrich, 2009:49). In contrast, Jayawardena and Liao (2006:129) claim that there is no direct link between elder abuse and the physical health condition of the older person. They view the increased frailty of the older person as a more precise risk factor for elder abuse than chronic health problems. 


\section{Presence of cognitive disorders}

Older people suffering from a cognitive disorder such as Alzheimer's disease and dementia may behave violently towards the caregiver, especially when the disease is progressing. It is important to note that the violent behaviour, and not the diagnosis of the cognitive disease, increases the chances of elder abuse (Jayawardena \& Liao, 2006:129; Lee \& Kolomer, 2005:69; Schiamberg \& Gans, 1999:90-91; Von Heydrich, 2009:50). In addition, a vulnerability to elder abuse also exists amongst older people with a memory impairment, which leads to their dependence on the perpetrator (Selwood et al., 2007:1009).

\section{Presence of mental or emotional illness}

Von Heydrich (2009:51) confirms that there is a strong cause-effect relationship between the emotional or psychological problem of the older person and elder abuse. According to Coyne et al. (cited by Kravitz, 2006:40), older people with mental and emotional illnesses may display violent and aggressive behaviour or may just be completely dependent on their caregiver, which leads to caregiver stress and burden that could result in elder abuse.

\section{Substance abuse}

Some people believe that they might enjoy good health if they use alcohol moderately, but excessive drinking may trigger psychiatric illnesses (Von Heydrich, 2009:52). According to Ananias and Strydom (2012), older people under the influence of alcohol and drugs may risk physical abuse because they may behave verbally abusively towards others. Schiamberg and Gans (1999:91) assert that older people who misuse alcohol are more vulnerable to elder abuse, since they are unable to care for or fend for themselves. In the same way, the huge amount of over-the-counter drugs and chronic medication taken by many older people could also have an addictive effect (Von Heydrich, 2009:52).

\section{Difficult behaviour}

Some older people have the tendency to be demanding, ungrateful and just difficult, which may result in aggressive behaviour on the part of the caregiver. Besides, older people with dementia may display aggressive and unpleasant behaviour because of cognitive, psychological or unmet emotional needs (Jayawardena \& Liao, 2006:129; Kravitz, 2006:43; Schiamberg \& Gans, 1999:91; Von Heydrich, 2009:53).

\section{Social isolation and loneliness}

According to Schiamberg and Gans (1999:95), older persons who are isolated from friends and relatives are at a greater risk of elder abuse, since the abusive behaviour remains hidden because there is no one to report the abuse. Some lonely older people develop relationships with unreliable strangers who may abuse them financially.

The older victim of abuse and neglect is thus a person with the following characteristics; an older male or female, of advanced age, who is abusing alcohol, displays violent or difficult behaviour, and suffers from a serious physical, cognitive or mental disorder. 


\section{- Individual characteristics: the perpetrator of elder abuse}

According to Bergeron (2001:53), the terms "caregiver" and "perpetrator" have become equivalent in elder abuse work, since perpetrators of elder abuse could be an adult child caring for an older relative, or a spouse caring for a frail partner. Even though more empirical evidence is needed, it seems that the adult child rather than the spousal caregiver is more likely to display potentially harmful behaviours towards the older parent (Rahman \& Gaafary, 2012:534; Sasaki et al., 2007:256). A better understanding of each of these risk factors associated with the caregiver will follow in the next section.

\section{Gender}

There are contradictory findings on the gender of the perpetrator and elder abuse, with various researchers having found both men and women could be perpetrators of elder abuse (Kravitz, 2006:46; Von Heydrich, 2009:44).

\section{Chronological age}

There are contradictory findings on age as a risk factor for elder abuse (Kravitz, 2006:46; Von Heydrich, 2009:44). In fact, Rahman and Gaafary (2012:536) assert that younger caregivers are more likely to commit acts of elder abuse and neglect than older caregivers.

\section{Psychological and emotional problems of the caregiver}

Some caregivers suffer from physical and mental illnesses, have developmental difficulties or are themselves in advanced age with dementia. Such caregivers may have good intentions but are not competent caregivers because of their inability to provide proper care, or to understand the consequences of poor care (Choi \& Mayer, 2000:5; Penhale, 2010:241; Schiamberg \& Gans, 1999:91).

\section{Substance abuse by the caregiver}

Caregivers with substance abuse problems make inappropriate decisions around their caregiving role, and may also misuse the finances of the older person, since buying alcohol will be the priority instead of caring for the older person (Jayawardena \& Liao, 2006:129; Schiamberg \& Gans, 1999:91).

The perpetrator of elder abuse and neglect could therefore be a male or female person, who suffers from a psychological or emotional problem, and is a substance abuser.

\section{- The caregiving context}

The interaction between the older person and the caregiver within the caregiving context also presents specific risk factors. They are discussed below.

\section{Lack of caregiver experience and reluctance}

Not all caregivers have experience in caring for an older person, since some people are forced by poor socio-economic circumstances or the need for care of an older family member and became caregivers against their will. Caregivers may have feelings of inadequacy and hostility because they lack experience in caregiving. Furthermore, caregivers might find it difficult to make financial, social, emotional, physical or mental 
sacrifices because of caregiving (Schiamberg \& Gans, 1999:91). Reluctance in the caregiver will also increase the feelings of incompetence regarding caregiving on the part of the caregiver, which may lead to elder abuse (Kravitz, 2006:50; Schiamberg \& Gans, 1999:91).

\section{Lack of support}

Caregivers with inadequate formal and informal support systems are at risk. It is thought that if caregivers do not receive any emotional support from the family or broader society, they may feel overwhelmed and become abusive (Kravitz, 2006:54; Schiamberg \& Gans, 1999:91). If the relationship between the caregiver and older person is tense because of violence, other family members and friends may be discouraged from visiting such a family member, which leads to further isolation and increased risk of elder abuse (Schiamberg \& Gans, 1999:95). Contrary to the findings of Kravitz (2006) and Schiamberg and Gans (1999) on the importance of support systems for informal caregivers, Lee (2008:711) found that informal support to family caregivers was no safeguard against elder abuse. According to Lee (2008), those family caregivers with high levels of informal social support were just as likely to abuse the older disabled person as caregivers without any support system, formal or informal.

\section{Past relationships between older person and caregiver}

There is some evidence that unhealthy past relationships between the adult child caregiver and older parent, characterised by actions of child abuse, domestic violence, inappropriate discipline, physical punishment and domestic violence could lead to elder abuse (Schiamberg \& Gans, 1999:94; Von Heydrich, 2009:41-42). Further empirical evidence for how past relationships can be a risk factor for elder abuse was found by Hughes (1997:53-60), who in a study of 43 caregivers of older people assessed how past abuse or violence before caregiving had commenced can impact the older personcaregiver relationship. Hughes (1997) identifies two risk factors for elder abuse, namely the mental health status of older people as well as a history of violence before caregiving had commenced. The study found that the mental health problems of the older person did not lead to elder abuse. However, violence before the commencement of caregiving was confirmed to be a risk factor for elder abuse.

Notwithstanding the findings of the studies cited above, some studies, notably that by Penhale (2010:242), have found intergenerational violence as a risk factor to elder abuse could not be verified. In fact, Penhale (2010) asserts that past relationships is a sensitive research topic and therefore difficult to research.

\section{Dependency}

Dependency as a risk factor for elder abuse has been debated at length. There are conflicting views about dependency as either a risk factor or a protective factor against elder abuse. Current studies tend to regard interdependency between the caregiver and the older person as a risk factor (Penhale, 2010:242; Schiamberg \& Gans, 1999:93). Society does not expect an adult caregiver to be dependent on the older person, but the caregiver may have feelings of discomfort, frustration and anger, which may lead to antisocial abusive behaviour (Horsford et al., 2010:79). An association between 
dependency and cognitive difficulties of older people was made by Nadien (2006:165), who states that some older people with poor cognitive functioning may display hostile and disturbing behaviour, such as constant complaining or asking the same questions repeatedly.

\section{Caregiver stress}

Some researchers (Lee, 2008:708; Penhale, 2010:241) claim that stress experienced by caregivers is a major risk factor for elder abuse. Fulfilling multiple roles in full-time employment, raising children as well as taking care of an older care recipient can be extremely stressful to the caregiver (Kravitz, 2006:51). Caregivers who experience stress may have good intentions to provide quality care, but if the expectations of care are higher than what is offered, caregivers may become verbally and physically abusive towards the older care recipient (Kravitz, 2006:51).

In contrast to the above studies, though, the World Health Organisation (2002:131) merely regards stress as a contributing factor, and not a risk factor for elder abuse. This view seems to suggest that the caregiver's perception of his or her own stress seems to be a more accurate risk factor than the actual burden of caregiving (Jayawardena \& Liao, 2006:129; Schiamberg \& Gans, 1999:91). Examples of caregiver stress that could lead to depression and elder abuse are, according to Smith et al. (2011:587-589), the poor physical health of the caregiver, manipulative and controlling behaviour of the older person, as well as restricted social contacts because of caregiving. The more stress experienced by the caregiver the higher the chances of the caregiver displaying verbally abusive behaviour such as screaming, yelling or threats towards the older person.

\section{Financial difficulties}

Lowenstein (2010:223) explains that providing care over a long period of time, without the necessary resources, can affect solidarity and exchange. The conflict and ambivalent feelings may as a result bring about negative caregiving outcomes such as elder abuse and neglect. Some caregivers may suffer economic difficulties if they have to resign from their jobs to take care of their elderly relatives. These caregivers may then develop feelings of resentment because they have lost their source of income (Schiamberg \& Gans, 1999:95). Von Heydrich (2009:55), points out that unemployed caregivers are financially dependent on the older person's housing and accommodation. While financially well off older people could be vulnerable to financial abuse (Peri et al., 2009:165), frail older people with fewer financial resources are at risk of neglect (Ayalon, 2011:503).

\section{Living arrangements}

Older people and caregivers who live in the same house have little privacy, and so older people are vulnerable to physical abuse (Yan \& Kwok, 2011:534). Wang et al. (2006:289) reason that conflict and tension are unavoidable between older people and caregivers who share the same household, which can thus lead to more frequent psychologically abusive behaviour. However, Pe'rez-Rojo et al. (2009:20) found no relationship between the risk for elder abuse and the fact that the caregiver and older person were sharing the same household. It is possible, though, that overcrowded living 
spaces may lead to family conflicts (Pe'rez-Roja et al., 2009:18; Schiamberg \& Gans, 1999:93-94). However, the literature seems to be silent on specific overcrowded situations in which older people share the same room with other members of multigenerational households.

The caregiving context that could place older people at risk of elder abuse and neglect thus includes the following: the inexperienced or reluctant caregiver, with an inadequate formal and informal support system, a history of dysfunctional relationships between the caregiver and care recipient, interdependency between the caregiver and care recipient, caregiver stress, financial difficulties, and co-resident living arrangements between the caregiver and care recipient.

\section{- Broader societal risk factors for elder abuse and neglect}

Social, economic and political factors make older people vulnerable to elder abuse and neglect. In addition, older people who lack resources, and who live in impoverished conditions, as well as those older people who experience inequalities because of race, gender and ageism are also vulnerable to elder abuse (Ferreira, 2004:20; Podnieks et al., 2010:156). Ferreira (2004:21) adds that widespread unemployment and lack of income have an impact on intergenerational relations and family harmony. Evidence from a qualitative study with older people, caregivers and service providers in New Zealand by Podnieks et al. (2010:159-172) confirms that ageism, older people's rights, gender roles and societal ideas of individuals and families are important themes of elder abuse at the broader societal level.

\section{Ageism}

Ageism or negative beliefs about older people and attitudes towards older persons, for example, beliefs that older people are weak, frail and dependent, could make them vulnerable to elder abuse (Kalache \& Blewitt, 2012:89). In western societies youth, beauty and health are considered to be of greater value than age. Because of this, older people may be perceived to be of lesser value and could be at risk of elder abuse (Schiamberg \& Gans, 1999:96; Von Heydrich, 2009:55). While some older people with negative self-perceptions may believe that they don't deserve respect, caregivers with negative perceptions and attitudes towards older people may also feel entitled to be abusive or neglectful (Nadien, 2006:165).

\section{Historical disadvantages}

Based on research in South Africa, it appears that violence occurs because of societal factors such as social disorder, crime, alcohol and drug abuse, poverty, lack of job opportunities, lack of education, and prostitution (World Health Organisation, 2002:132). According to Horsford et al. (2010:78), contextual factors unique to AfricanAmerican communities that contribute to elder abuse are historical disadvantages such as racial discrimination, structural segregation, or anger and hopelessness associated with economic and health disparities. The broader societal risk factors to elder abuse within the Namibian context have similarities with the South African and AfricanAmerican communities. According to Dima (2003:1), as a result of the historical and political background, indigenous older people were marginalised in terms of equal 
access to basic social services such as education, health and employment. The draft green paper from the Ministry of Health and Social Services (1997:P1-1) further states that previously marginalised Namibians continue to live under poor socio-economic conditions as they are aging.

\section{PROTECTIVE FACTORS WITH RESPCT TO ELDER ABUSE AND NEGLECT}

Whereas the literature largely concentrates on the risk factors to elder abuse and neglect, very little attention has been paid to the protective factors with respect to elder abuse and neglect. There are factors within family settings that can reduce the chances of elder abuse. Nadien (2006:158) claims that caregivers who are not suffering from any mental illness or personality disorder, and who abstain from alcohol and drugs, are less likely to be abusive towards older care recipients. In addition, caregivers who have received some form of training to cope with the stress of caregiving or to cope with provocative or abusive behaviour from the older person can also be seen as a protective factor against elder abuse. Finally, caregivers who receive adequate remuneration and support are less likely to display abusive behaviour towards the older person.

Horsford et al. (2010:83-85) claim that, at the broader societal level, communities characterised by a strong sense of community, spirituality and resilience, loyalty to family, value of motherhood and appreciation of the elderly are less likely to abuse older people. A strong sense of community can be created through the extended family, the church community and neighbours who are a source of support during times of distress. Spirituality and resilience can offer strength, support and comfort to both the older person and the caregiver. Peri et al. (2009:166) emphasise that practical suggestions concerning protective factors against elder abuse are, amongst others, the treatment of older people with respect, the education of communities on the aging process, promoting the needs and rights of older people, and improvement in the coordination of policies and services for older people.

\section{RESPONSES TO ELDER ABUSE AND NEGLECT}

Based on the discussions of the risk and protective factors related to elder abuse and neglect, appropriate responses to elder abuse must be designed that target the various systems according to the ecological perspective.

Within the informal caregiving context in particular, Nadien (2006:166) proposes that the offering of social support and respite care to caregivers can reduce caregiver stress tremendously. Additionally, Ackermann and Matebesi (1998:24) argue that day care and emotional support services need to be developed to reduce caregivers stress.

Many scholars suggest support group interventions with caregivers as a proper intervention to reduce elder abuse and neglect (Ackermann \& Matebesi, 1998:24; Lee, 2008:711; Sasaki et al., 2007:55; Smith et al., 2011:589). These scholars argue that support group interventions with informal caregivers of older people can be of great value. The value lies in the fact that support groups can reduce the caregiving burden by linking caregivers with community resources (Wang et al., 2006:289). Support groups also engage caregivers in social activities that can reduce isolation (Smith et al., 
2011:589). Another intrinsic value of support groups is that they provide platforms for caregivers to exchange skills and share coping strategies among caregivers (Lee, 2008:711). Finally, support groups can offer psychosocial support and problem-solving skills (Ackermann \& Matebesi, 1998:24).

In spite of the foregoing arguments, Post et al. (2010:339) posit that effective interventions with respect to elder abuse and neglect have not yet been developed. In addition, Ploeg et al. (2009:206) maintain that there is a lack of high-quality research on the effectiveness of elder abuse interventions, since most elder abuse intervention studies are descriptive by nature and do not include a comparison group.

\section{CONCLUSION}

This article provided an overview of the contributing factors to elder abuse and neglect within the informal caregiving setting. Ecological theory offered a comprehensive understanding of the wider range of risk factors that contribute to elder abuse and neglect. Elder abuse and neglect may be addressed properly only if combined actions are taken by various role-players to respond to risk factors across all systems as stated in ecological theory, which ultimately can result in multidisciplinary research as well as the design and implementation of appropriate interventions. More research on protective factors against elder abuse and neglect is needed, since protective factors can be critically important in the prevention of elder abuse and neglect.

\section{REFERENCES}

ACKERMANN, L. \& MATEBESI, Z. 1998. Experiences of co-resident carers of elderly persons in Mangaung (Bloemfontein). Southern African Journal of Gerontology, $7(1): 21-25$.

ANANIAS, J.A. \& STRYDOM, H. 2012. Informal caregiving, elder abuse and neglect in urban and rural areas of the Khomas region in Namibia: a needs assessment. (Unpublished).

ANETZBERGER, G.J. 2005. The reality of elder abuse. Clinical Gerontology, 28(12):1-25.

AYALON, L. 2011. Abuse is in the eyes of the beholder: using multiple perspectives to evaluate elder mistreatment under round-the-clock foreign home carers in Israel. Ageing and Society, 31:499-520.

AYRES, M. M. \& WOOODTLI, A. 2001. Concept analysis: abuse of ageing caregivers by elderly care recipients. Journal of Advanced Nursing, 35(3):326-334. 
BERGERON, L.R. 2001. An elder abuse case study: caregiver stress or domestic violence? You decide. Journal of Gerontological Social Work, 34(4):47-63.

BROOK, G. 2008. Elder abuse and neglect: past endeavours as a springboard for the future. Aotearoa New Zealand Social Work, 3:44-51.

CHOI, N.G. \& MAYER, J. 2000. Elder abuse, neglect, and exploitation: risk factors and prevention strategies. Journal of Gerontological Social Work, 33(2):5-25.

CONRAD, K.J., IRIS, M., RIDINGS, J.W., ROSEN, A., FAIRMAN, K.P. \& ANETZBERGER, G.J. 2011. Conceptual model and map of psychological abuse of older adults. Journal of Elder Abuse and Neglect, 23(2):147-168.

DE DONDER, L., LANG, G., LUOMA, M., PENHALE, B. ALVES, J.F., TAMUTIENE I., SANTOS, A.J., KOIVUSILTA, M., ENZENHOFER, E., PERTTU, S., SAVOLA, T. \& VERTE, D. 2011. Perpetrators of abuse against older women: a multinational study in Europe. The Journal of Adult Protection, 13(6):302-314.

DIMA, E. 2003. Models of Institutional Care for the Elderly in Namibia. Windhoek: UNAM. (MA Dissertation).

FERREIRA, M. 2004. Aging, support and care in Africa: how feasible are high standards in low economics? Bold, 14(2):5-10.

HABJANIC, A. \& LAHE, D. 2012. Are frail older people less exposed to abuse in nursing homes as compared to community-based settings? Statistical analysis of Slovenian data. Archives of Gerontology and Geriatrics, 54:261-270.

HEMPTON, C., DOW, B., CORTES-SIMONET, E.N., ELLIS, K., KOCH, S., LOGIUDICE, D., MASTWYK, M., LIVINGSTON, G., COOPER, C. \& AMES, D. 2011. Contrasting perceptions of health professionals and older people in Australia: what constitutes elder abuse? International Journal of Geriatric Psychiatry, 26:466472 .

HORSFORD, S.R., PARRA-CARDONA, J.R., LORI, A., POST, L.A. \& SCHIAMBERG, L. 2010. Elder abuse and neglect in African American families: 
informing practice based on ecological and cultural frameworks. Journal of Elder Abuse and Neglect, 23(1):75-88.

HUGHES, M. 1997. "That triggers me right off": factors influencing abuse and violence in older people's caregiving relationships. Australian Journal on Aging, 16(2):53-60.

JAYAWARDENA, K.M. \& LIAO, S. 2006. Elder abuse at end of life. Journal of Palliative Medicine, 9(1):127-137.

KALACHE, A. \& BLEWITT, R. 2012. Human rights in older age. In: GLOBAL AGENDA COUNCIL ON AGEING SOCIETY (eds) Global population aging: peril or promise. Geneva: World Economic Forum, 89-92.

KRAVITZ, J.A. 2006. The safe elder scales: identifying high risk cases of elder abuse. Culver City, CA: Pepperdine University. (PhD Thesis)

LEE, M. 2008. Caregiver stress and elder abuse among Korean family caregivers of older adults with disabilities. Journal of Family Violence, 23:707-712.

LEE, M. \& KOLOMER, S. 2005. Caregiver burden, dementia and elder abuse in South Korea. Journal of Elder Abuse and Neglect, 17(1):61-74.

LOWENSTEIN, A. 2010. Caregiving and elder abuse and neglect - developing a new conceptual perspective. Ageing International, 35:215-227.

LOWENSTEIN, A., EISIKOVITS, Z., BAND-WINTERSTEIN, T. \& ENOSH, G. 2009. Is elder abuse and neglect a social phenomenon? Data from the first national prevalence survey in Israel. Journal of Elder Abuse and Neglect, 21(3):253-277.

MILEY, K.K., O’MELIA, M. \& DU BOIS, B. 2004. Generalist social work practice: an empowering approach. New York: Pearson Allyn and Bacon.

MINISTRY OF HEALTH AND SOCIAL SERVICES. 1997. Situation on social welfare policies in Namibia. Volume 1: Summary and recommendations. The Green Paper Draft 1. 
MOUTON, C.P., LARME, A.C., ALFORD, C.L., TALAMANTES, M.A., McCORKLE, R.J. \& BURGE, S.K. 2005. Multiethnic perspectives on elder mistreatment. Journal of Elder Abuse and Neglect, 17(2):21-44.

NADIEN, M.B. 2006. Factors that influence abusive interactions between aging women and their caregivers. Annals New York Academy of Sciences, 1087:158-169.

PENHALE, B. 2010. Responding and intervening in elder abuse and neglect. Ageing International, 35:235-252.

PE`REZ-ROJO, G., IZAL, M., MONTORIO, I. \& PENHALE, B. 2009. Risk factors of elder abuse in a community dwelling Spanish sample. Archives of Gerontology and Geriatrics, 49:17-21.

PERI, K., FANSLOW, J., HAND, J. \& PARSON, J. 2009. Keeping older people safe by preventing elder abuse and neglect. Social Policy Journal of New Zealand, 35:159172.

PIERSON, J. \& THOMAS, M. 2010. Dictionary of Social Work: the Definitive A to Z of Social Work and Social Care. New York: McGraw Hill.

PLOEG, J., FEAR, J., HUTSCHISON, M.D., MacMILLAN, H. \& BOLAN, G. 2009. A systematic review of interventions for elder abuse. Journal of Elder Abuse and Neglect, 21(3):187-210.

PODNIEKS, E., PENHALE, B., GOERGEN, T., BIGGS, S. \& HAN, D. 2010. Elder mistreatment: an international narrative. Journal of Elder Abuse and Neglect, 22(12):131-163.

POST, L., PAGE, C., CONNER, T., PROKHOROV, A., FANG, Y. \& BIROSCAK, B.J. 2010. Elder abuse in long-term care: Types, patterns, and risk factors. Research on Aging, 32(3):323-348.

RAHMAN, T.T.A. \& GAAFARY, M.M.E. 2012. Elder mistreatment in a rural area in Egypt. Geriatric Gerontology International, 12:532-537. 
RICHARDSON, B., KITCHEN, G. \& LIVINGSTON, G. 2002. The effect of education on knowledge and management of elder abuse: a randomized controlled trial. Age and Ageing, 31:335-341.

SASAKI, M., ARAI, Y., KUMAMOTO, K., ABE, K., ARAI, A. \& MUZUNO, Y. 2007. Factors related to potentially harmful behavior towards disabled older persons by family caregivers in Japan. International Journal of Geriatrics, 22:250-257.

SCHIAMBERG, L.B. \& GANS, D. 1999. An ecological framework for contextual risk factors in elder abuse by adult children. Journal of Elder Abuse and Neglect, 11(1):79103.

SCHIAMBERG, L.B., BARBOZA, G.G., OEHMKE, J., ZHANG, Z., GRIFFORE, R.J., ROBIN, P., WEATHERILL, R.P., VON HEYDRICH, L. \& POST, L.A. 2011. Elder abuse in nursing homes: an ecological perspective. Journal of Elder Abuse and Neglect, 23(2):190-211.

SELWOOD, A., COOPER, C. \& LIVINGSTON, G. 2007. What is elder abuse - who decides? International Journal of Geriatric Psychiatry, 22:1009-1012.

SEV'ER, A. 2009. More than wife abuse that has gone old: a conceptual model for violence against the aged in Canada and the US. Journal of Comparative Family Studies, 40(2):279-292.

SHIELDS, C. 2010. Elder abuse and caregiver stress: an exploration of the relationship from the perspective of the marginalized elders and their caregivers. Alberta: University of Calgary. (MA Dissertation)

SIBAI, A. \& YAMOUT, R. 2012. Family-based old-age care in Arab countries: between tradition and modernity. In: GROTH, H. \& SOUSA-POZA, A. (eds) Population dynamics in Muslim countries: assembling the jigsaw. Switzerland: Springer, 63-76.

SMITH, G.R., WILLIAMSON, G.M., MILLER, L.S. \& SCHULZ, R. 2011. Depression and quality of informal care: a longitudinal investigation of caregiving stressors. Psychology and Aging, 26(3):584-591. 
STRYDOM, H. 2003. Perceptions and attitudes towards elder abuse. Die Maatskaplikewerk-Navorser/Praktisyn / The Social Work Practitioner/Researcher, 15(1):76-96.

TEATER, B. 2010. An introduction to applying social work theories and methods. New York: McGraw Hill Open University Press.

VAN RENSBURG, S.J. \& STRYDOM, H. 2010. Profiel en betrokkenheid van afgetrede vrywilligers by ' $\mathrm{n}$ nie-winsgewende organisasie. Social Work/Maatskaplike Werk, 46(3):381-394.

VON HEYDRICH, L. 2009. An ecological bi-focal model for elder physical abuse by adult child: a structural equation modeling of risk factors predicting elder abuse in the United States. Michigan State University. (Thesis PhD)

WALSH, C.A. \& YON, Y. 2012. Developing an empirical profile for elder abuse research in Canada. Journal of Elder Abuse and Neglect, 24(2):104-119.

WANG, J.J., LIN, J.N. \& LEE, F.P. 2006. Psychological abusive behavior by those caring for the elderly in a domestic context. Geriatric Nursing, 27(5):284-291.

WEEKS, L.E., RICHARDS, J.L., NILSSON, T., KOZMA, A. \& BRYANTON, O. 2005. A gendered analysis of the abuse of older adults: evidence from professionals. Journal of Elder Abuse and Neglect, 16(2):1-15.

WORLD HEALTH ORGANIZATION (WHO). 2002. Report on Violence and Health. Geneva: WHO.

YAN, E. \& KWOK, T. 2011. Abuse of older Chinese with dementia by family caregivers: an inquiry into the role of caregiving burden. International Journal of Geriatric Psychiatry, 26:527-535.

Ms Janetta Ananias, Department of Social Work, University of Namibia, Windhoek; Prof Herman Strydom, School for Psychosocial Behavioural Sciences, North-West University, Potchefstroom Campus, South Africa. 
